\title{
BMJ Global Health Lessons learned from the development and implementation of an electronic paediatric emergency and acute care database in Lilongwe, Malawi
}

\author{
Emily J Ciccone (D , ${ }^{1}$ Alyssa E Tilly, ${ }^{2}$ Msandeni Chiume, ${ }^{3}$ Yamikani Mgusha, ${ }^{3}$ \\ Michelle Eckerle, ${ }^{4}$ Howard Namuku, ${ }^{5}$ Heather L Crouse, ${ }^{6}$ Treasure B Mkaliainga, ${ }^{3}$ \\ Jeff A Robison, ${ }^{7}$ Charles J Schubert, ${ }^{8}$ Tisungane Mvalo, ${ }^{9,10}$ \\ Elizabeth Fitzgerald (D) ${ }^{11}$
}

To cite: Ciccone EJ, Tilly AE, Chiume M, et al. Lessons learned from the development and implementation of an electronic paediatric emergency and acute care database in Lilongwe, Malawi. BMJ Global Health 2020;5:e002410. doi:10.1136/ bmjgh-2020-002410

Handling editor Seye Abimbola

Received 16 February 2020

Revised 23 April 2020

Accepted 9 May 2020

\section{Check for updates}

(c) Author(s) (or their employer(s)) 2020. Re-use permitted under CC BY-NC. No commercial re-use. See rights and permissions. Published by BMJ.

For numbered affiliations see end of article.

Correspondence to

Dr Emily J Ciccone; ciccone@med.unc.edu

\section{ABSTRACT}

As the field of global child health increasingly focuses on inpatient and emergency care, there is broad recognition of the need for comprehensive, accurate data to guide decision-making at both patient and system levels. Limited financial and human resources present barriers to reliable and detailed clinical documentation at hospitals in lowand-middle-income countries (LMICs). Kamuzu Central Hospital $(\mathrm{KCH})$ is a tertiary referral hospital in Malawi where the paediatric ward admits up to 3000 children per month. To improve availability of robust inpatient data, we collaboratively designed an acute care database on behalf of PACHIMAKE, a consortium of Malawi and US-based institutions formed to improve paediatric care at $\mathrm{KCH}$. We assessed the existing health information systems at $\mathrm{KCH}$, reviewed quality care metrics, engaged clinical providers and interviewed local stakeholders who would directly use the database or be involved in its collection. Based on the information gathered, we developed electronic forms collecting data at admission, follow-up and discharge for children admitted to the $\mathrm{KCH}$ paediatric wards. The forms record demographic information, basic medical history, clinical condition and pre-referral management; track diagnostic processes, including laboratory studies, imaging modalities and consults; and document the final diagnoses and disposition obtained from clinical files and corroborated through review of existing admission and death registries. Our experience with the creation of this database underscores the importance of fully assessing existing health information systems and involving all stakeholders early in the planning process to ensure meaningful and sustainable implementation.

\section{INTRODUCTION}

Nearly 6 million children under 5 years die each year worldwide, and that burden is disproportionately borne by those in lowand-middle-income countries (LMICs). ${ }^{1}$ In resource-constrained settings in sub-Saharan Africa (SSA), acute and emergency facilities
Summary box

There is an urgent need for comprehensive, accurate data about paediatric emergency and acute care in low-and-middle-income countries.

- This information is key to improving quality of care and informing practice guidelines and policies.

- We developed an electronic emergency and acute care database to augment the collection of clinical and process data for quality improvement in the paediatrics department at a large referral hospital in Malawi.

- Careful assessment of the existing local health information systems, early engagement of all stakeholders and adaptability were key to its sustainable implementation.

are often the primary providers of paediatric medical care. Despite this fact, acute care has been neglected in many of the initiatives put forth to improve child survival. ${ }^{2}$ Adherence to the WHO guidelines is often suboptimal, with deficient or absent triage of patients, emergency care and inpatient management. ${ }^{3-5}$ Furthermore, there are inadequate numbers of clinical providers and basic medications and supplies. ${ }^{6}$ Poor quality of care has become an even greater barrier to mortality reduction than inadequate access to healthcare.

To decrease paediatric morbidity and mortality, there is an increasing focus on strengthening the quality of global emergency and acute inpatient health services. ${ }^{6-11}$ However, robust data to guide and evaluate system improvement interventions in SSA is limited. $^{1213}$ Quality data are necessary for action and accountability ${ }^{14}$; without reliable information, it is challenging to make informed decisions about resource allocation 
and process improvement. We, and others, have found that health system data collection is often costly, uncoordinated and disconnected from decision-making and has missing or inaccurate data. ${ }^{815-18}$ In 2010, eight prominent health agencies advocated for improved quality of data to facilitate health performance monitoring and health interventions impact assessment. ${ }^{13}$ To accomplish this, it is critical to develop reliable data collection systems that provide accurate information about patients, diseases and treatment outcomes. ${ }^{14} 19$

Here, we describe the creation of an electronic paediatric acute care database at Kamuzu Central Hospital $(\mathrm{KCH})$ in Lilongwe, Malawi. This database was created on behalf of the Paediatric Alliance for Child Health Improvement in Malawi at KCH and Environs (PACHIMAKE), a consortium of Malawi and US-based institutions formed in 2016 to leverage the resources of institutions working in paediatric emergency care at $\mathrm{KCH}$ to improve care quality. ${ }^{20}$ At initial meetings, $\mathrm{KCH}$ paediatric administrators and clinicians noted that there was little known about the relative burden of diseases and the specifics of clinical care being provided in the inpatient setting. They therefore identified the department's most pressing need as the collection of more comprehensive data to identify areas of inadequate or inconsistent care provision, serve as a baseline for future quality improvement (QI) interventions, assess effectiveness of these interventions and support external funding applications. To address this need, we developed the acute care database. Its primary objective was to improve the completeness, breadth and accessibility of information collected about paediatric acute and emergency care at $\mathrm{KCH}$.

\section{HEALTH INFORMATION SYSTEMS IN SUB-SAHARAN AFRICA}

In resource-constrained settings, most systems collecting patient-level health information have employed paper forms. ${ }^{21}{ }^{22}$ Paper data collection is feasible in lowresource contexts as it is not dependent on data entry equipment, electricity or internet availability, it mimics the format of clinical records, and it can be carried out by clerks with minimal clinical or information technology training. However, this method's reliability is uncertain, as has been noted in Malawi specifically, ${ }^{23}$ and it is not conducive to real-time data analysis or feedback to clinical providers. ${ }^{24}$ Additionally, monitoring and evaluation of national programmes targeting improvement of health outcomes are challenging as paper forms require manual aggregation by data clerks or health information systems staff.

To improve ease of access to clinical information and increase the scope of gathered data, electronic data collection tools and databases have been developed in SSA. Most of these systems have primarily focused on HIV/AIDS, other infectious diseases, or specific conditions or patient populations such as newborn health or traumatic injuries. ${ }^{172122}{ }^{25-29}$ Some systems have worked to integrate data from these disease-specific programmes into existing aggregate electronic systems, specifically the District Health Information System 2 (DHIS2), an online, open-source software for reporting and organisation of data collected at health facilities that has been implemented across SSA. ${ }^{30}$

Fewer data collection systems, however, have sought to broadly document acute and/or emergency care. In Malawi, researchers at Queen Elizabeth Central Hospital in Blantyre (the tertiary referral hospital for the southern region of the country) demonstrated the feasibility and utility of an electronic database for the adult internal medicine wards. ${ }^{24}$ In Kenya, Mike English and colleagues developed an electronic clinical data management tool to document and support inpatient paediatric care within the Clinical Information Network, which includes 14 district-level hospitals throughout the country. ${ }^{31}$ Review of the experiences of these groups and others informed the design and implementation of our database in the KCH Paediatric Department.

\section{PAEDIATRIC ACUTE CARE AT KCH}

$\mathrm{KCH}$ is the tertiary facility for the central region of Malawi, a catchment area of approximately 7.5 million people. ${ }^{32}$ There are four such facilities in the country, serving as referral hospitals for all district hospitals in their respective regions. ${ }^{33}$ Although patients are charged 'bypass fees' if they present directly to tertiary facilities without referral, there is no true gatekeeping system, and referral hospitals, including $\mathrm{KCH}$, therefore also provide primary and secondary level services. ${ }^{33}{ }^{34}$ The majority of paediatric patients older than 2 weeks of age presenting to $\mathrm{KCH}$ are initially seen at the Under 5 (U5) clinic, which serves as the triage area, paediatric outpatient department and primary source of inpatient admissions (figure 1). However, it is not uncommon for patients to enter the hospital ward directly, bypassing U5 and its triage system.

Paediatric patients with trauma are also evaluated in a separate area. Those who are treated and discharged home from U5 are considered outpatients, whereas those who require further treatment or monitoring after initial evaluation are admitted to the hospital as inpatients. Approximately 200-400 patients are seen in the U5 clinic each day, leading to more than 27,000 admissions each year. A triage system based on the WHO's Emergency Triage, Assessment, and Treatment (ETAT) guidelines was implemented in U5 in 2009-2010. ${ }^{35}$ This change was associated with a substantial decrease in mortality; however, current rates remain unacceptably high, and the regular practice of ETAT has waned. ${ }^{36}$

\section{EXISTING HEALTH INFORMATION SYSTEMS AT KCH}

Prior to designing the database, it was important to first understand the existing systems for health information collection and storage in the $\mathrm{KCH}$ Paediatric Department. This was to ensure that the planned database 


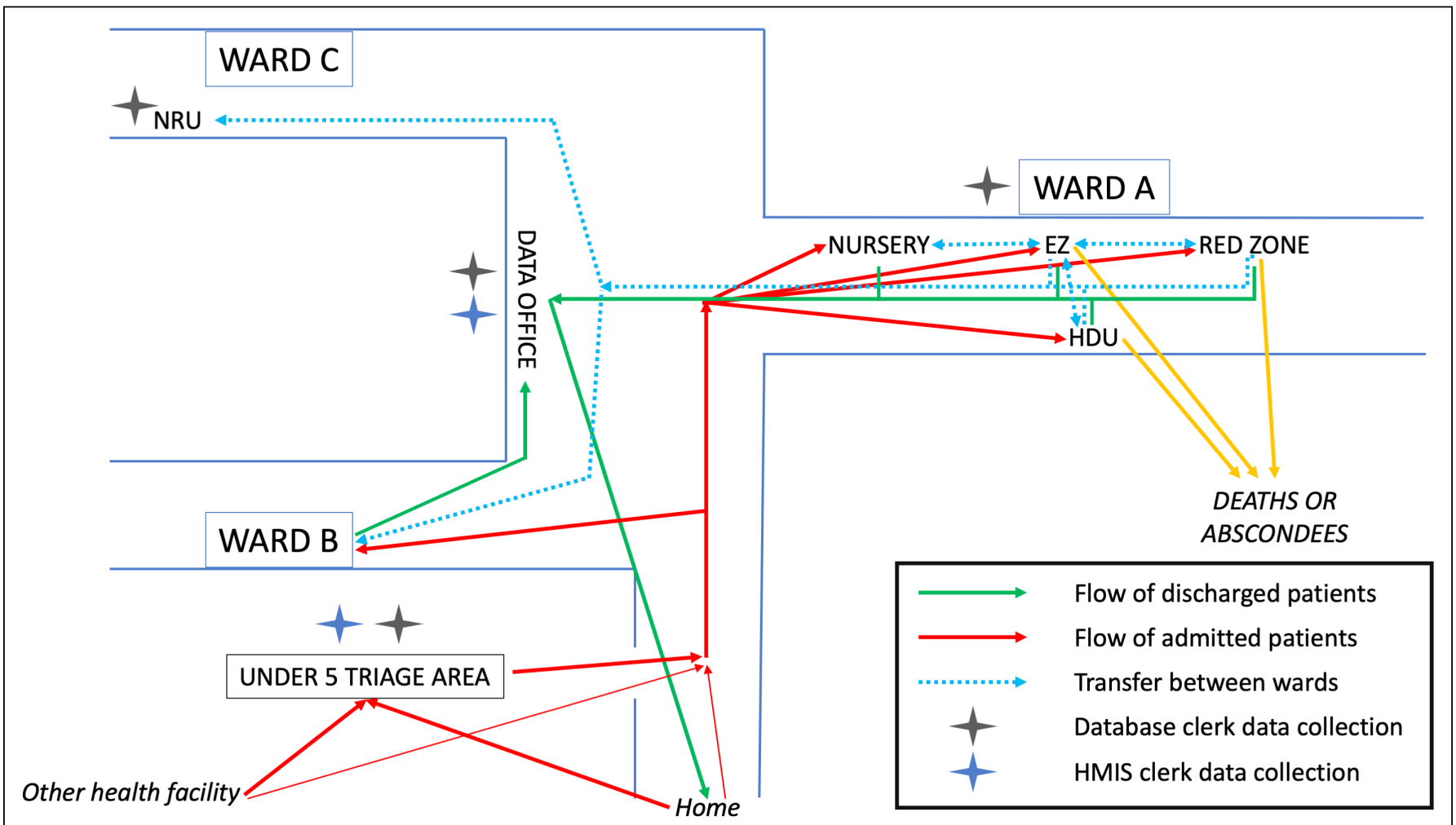

NRU - Nutritional Rehabilitation Unit; EZ - Emergency Zone; HDU - High Dependency Unit

Figure 1 Diagram of the paediatric inpatient wards at Kamuzu Central Hospital in Lilongwe, Malawi. Arrows outline the potential paths for paediatric patients older than two weeks of age presenting for emergency or acute care (excluding trauma).

augmented the existing system and allowed for collaboration with and engagement of current staff.

The Health Sector Strategic Plan for Malawi includes as a key component the provision of reliable, complete, accessible, timely and consistent health information to be used for evidence-based decision-making at all levels of the health system. ${ }^{33}$ At the national level, DHIS2 is employed for reporting and organisation of health information. ${ }^{23} 3738$ Aggregate data from each health centre are sent, often on paper, to the Health Management Information System (HMIS) officer at the district office, who then enters the information into DHIS2 ${ }^{39}$ However, at the time of our database's development, health indicators from tertiary hospitals had a separate reporting system and were not yet fully incorporated into DHIS2. ${ }^{23}$ This integration of tertiary care data is still in process at time of publication.

At KCH, the patient-level information is collected in register books by each clinical department and summarised on reporting forms, which are submitted to the HMIS department. Spreadsheet and word processor software are used to generate reports. Required statistics (e.g. number of admissions, number of operations and common diagnoses) are reported on request to the Central Monitoring and Evaluation Division at the Ministry of Health (MOH).

Paediatric emergency and acute care data are therefore primarily collected in two places: the government registers of the HMIS department and paper clinical charts. In
U5, the Paediatric Department's HMIS data clerks assign a unique identifier to each patient and enter them into an HMIS register book. The identifier is also recorded on the patient's clinical file, if admitted. The numbering system resets each year. If a patient is admitted more than once within the same year for the same reason, for example, malaria, they will be followed using the same HMIS number. Each patient is assigned a new HMIS number every year or if they are evaluated twice in the same year for different reasons.

In U5, the HMIS clerks collect basic demographic and clinical information including age, name of referral facility, reason for admission (if admitted to the inpatient ward) and any treatment administered (if discharged after initial evaluation) in the register books. Those who are discharged home are entered in a separate book from those who are admitted. In addition, the treating clinician in U5 starts a paper clinical file for admitted patients where the details of evaluation and management while admitted are documented. When discharged from $\mathrm{KCH}$, the guardians are requested to leave the clinical file at the paediatric ward's data office (figure 1). There, the HMIS clerks record the final diagnosis, length of stay, 'summary of treatment,' and if a surgical procedure was performed in a discharge register. There is a separate register for those who die while hospitalised containing only very limited clinical information. The clinical files are stored grouped by month and disposition (discharge or death). 
In summary, the government HMIS at KCH consists of multiple paper registers that include only basic information and may not be reliable for estimating trends in mortality. ${ }^{40}$ Furthermore, a recent audit of paediatric death files at KCH found multiple deficiencies in documentation in the clinical files including referral information, vital signs, and outcomes of laboratory, imaging, and specialty consultations. ${ }^{41}$ It is also not uncommon for guardians to inadvertently take the files home, leading to incomplete outcome data. Therefore, for the paediatric department to use these sources to inform QI initiatives or track trends, it must manually aggregate the patientlevel data, a time-consuming, inefficient and potentially unreliable process.

\section{EXISTING PATIENT DATABASES AT KCH}

Successful research-oriented patient databases have been implemented at $\mathrm{KCH}$ in other departments, including Medicine and Surgery. These are described elsewhere and have provided useful information about targeted prevention measures. ${ }^{42-44}$ Through meetings with key personnel responsible for these databases, we learnt their implementation logistics and ongoing processes. We assessed data collection forms, which influenced the production of our database forms. We also shadowed data officers working with the surgery database to observe workflow and integrated their suggestions for overcoming the challenges encountered during implementation.

\section{ACCREDITOR AND STAKEHOLDER ASSESSMENTS}

Crucial to the success of our database was early engagement of all stakeholders. We identified nursing staff, paediatric consultants, department administrators, clinical officers (COs), interns and other learners rotating on the wards, as well as the government-employed HMIS data clerks, as the key stakeholders. We conducted meetings with all groups to review what data were already being recorded in the HMIS registers and received verbal feedback on what additional information should be included. In addition, a subset of COs, intern medical officers, nurses and $\mathrm{CO}$ bachelor students completed written questionnaires (table 1). The stakeholders identified socioeconomic information, initial presentation, inpatient testing and clinical outcomes as additional priorities. Through this process, we identified interested Malawian clinicians to be 'champions' supporting database implementation. These individuals are COs who serve as a clinical resource for the data clerks and conduct audits to ensure data quality; there is one person assigned to this role at any given time during database implementation. Finally, we made sure to review and include pertinent metrics and standards assessed by the only internationally accredited QI and accreditation body for healthcare facilities in SSA, the Council for Health Service Accreditation of Southern Africa (COHSASA).

\section{PAEDIATRIC EMERGENCY AND ACUTE CARE DATABASE}

Using the information gleaned from the groundwork described above, we designed and planned the database to inform the development of specific QI interventions targeted at modifiable barriers to care, with the ultimate goal of building on previous improvements in inpatient mortality. Specifically, we had the following aims:

1. Describe the demographics and initial clinical presentation of all children ages 6 months to 3 years (later expanded to ages 2 weeks to 5 years) acutely admitted to KCH Department of Paediatrics.

2. Describe the initial testing and interventions provided to patients on admission.

3. Obtain accurate and thorough outcomes data, including discharge diagnoses, medications prescribed and patient education provided.

4. Identify modifiable gaps in the provision of care to acutely ill paediatric patients, by identifying delays in labs, blood transfusions, investigations and consults.

\section{Form development and evolution}

We developed the data collection forms in collaboration with the KCH clinicians, HMIS leadership and representatives from the PACHIMAKE institutions. They were based on the aforementioned questionnaire, free-form small group discussions, existing clinical forms and HMIS registers, and review of COHSASA metrics. We designed the electronic form using the Research Electronic Data Capture (REDCap) application, a secure web-based platform for building and maintaining online databases, ${ }^{45}$ which was also used for similar purposes in Kenya. ${ }^{31}$ It has mobile app functionality that allows for offline data entry. The database project was approved by the University of North Carolina (UNC) Institutional Review Board and the National Health Science Research Committee in Malawi. The requirement for consent was waived because the information being collected in the database is routine clinical data.

The database data clerks are employed through UNC Project-Malawi, a collaboration between UNC, the Malawi $\mathrm{MOH}$ and $\mathrm{KCH}$ located on KCH's campus. During a pilot of several months, the clerks collected data on paper forms. They then transitioned to using tablets to directly enter data into the electronic REDCap forms. We have modified the variables assessed several times over the course of the project based on clerk and departmental feedback to ensure data quality and improve clerk efficiency. The full list of currently collected variables is listed in table 2.

\section{Patient population}

The database was first implemented in the $\mathrm{KCH}$ paediatric wards in September 2017 and is ongoing at the time of this publication. From September 2017 to December 2018, we followed all patients aged 6 months to 3 years who were admitted for inpatient evaluation and treatment. Funding limitations required us to initially restrict our age cohort, and this age range was chosen 
Table 1 Questions and example responses from free-form, paper questionnaires completed by key stakeholders during planning of the paediatric acute care database. In total, this survey was completed by six intern medical officers, one nutritionist, one paediatric clinical officer bachelor student, four clinical officers and two nurses. The questionnaires were designed by authors EJC and AET.

\begin{tabular}{ll}
\hline Question & Example Responses \\
\hline $\begin{array}{l}\text { Beyond what is currently collected*, what additional data } \\
\text { would you like to see gathered? }\end{array}$ & "I would like to see if you can collect blood transfusion data. \\
& Thus, whether child required a transfusion and if child actually \\
got the blood transfusion" (Intern medical officer) & "Height, MUAC [middle upper arm circumference]" (Intern \\
& medical officer) \\
& "Medication administered pre-referral" (Intern medical officer) \\
& "On patients who are discharged, if possible to include date of \\
& review if necessary and when to come back for review in clinic" \\
& (Clinical officer) \\
& "HIV and nutrition assessment in under 5 and discharge book" \\
& (Clinical officer) \\
& "Deaths of patients referred" (Nurse)
\end{tabular}

Are there any specific conditions for which you would like $>$ "RBS [random blood sugar] and Hb [hemoglobin] in anyone with more in-depth data to be collected? If yes, what particular information are you interested in? a diagnosis of malaria" (Intern medical officer)

- "Recognition of need for NRU [Nutritional Rehabilitation Unit] assessment on admission in malnutrition-related deaths" (Intern medical officer)

- "Malaria - role of early blood transfusion in cerebral malaria" (Clinical officer)

- "Heart conditions - use of cardiac medication, antibiotics in RHD [rheumatic heart disease]" (Intern medical officer)

- "Diabetes - insulin/medications" (Nurse)

\begin{tabular}{|c|c|}
\hline $\begin{array}{l}\text { How with the data from this database be useful for you? } \\
\text { How do you hope to use it? }\end{array}$ & $\begin{array}{l}\text { "Influencing policies on management at primary health centres } \\
\text { for example, health centres..." (Intern medical officer) } \\
\text { "Will help us to improve our data quality....and patients care" } \\
\text { (Nurse) } \\
\text { "The data is [sic] like a microscope which will help us to see } \\
\text { where we are weak and where to improve on and do much } \\
\text { better" (Clinical officer) } \\
\text { "Act as a baseline and reference for future improved [sic] and } \\
\text { research" (Clinical officer) } \\
\text { "To determine how many malnourished children admitted per } \\
\text { year. Prepare for therapeutic supplies" (Nutritionist) }\end{array}$ \\
\hline
\end{tabular}

*Questionnaire respondents were provided with a list of the variables currently collected in the Health Management Information System Admission and Discharge books.

by the Head of Department as the group at highest risk of mortality excluding neonates. In January 2019, we expanded to include all children aged 2 weeks to 5 years. Children under 2 weeks were not included because they are triaged and admitted in a different building from the other paediatric patients, and their existing health information system is separate from that of the other paediatric patients.

\section{Procedures}

The database data clerks underwent training on how to (1) collect patient data from the medical files and patient caregivers; (2) obtain vital signs and measure anthropometric statistics including weight, height and mid-upper arm circumference when clinicians do not; and (3) conduct an ETAT evaluation to recognise a sick child. They are stationed in U5 24 hours a day, 7 days a week alongside the HMIS clerks. Each database record represents one admission for one patient, and each admission is assigned a unique database ID. The database clerks document demographic information, clinical presentation, initial diagnostic evaluation and interventions at the time of patient triage (table 2) through direct interaction with patient guardians and review of the clinical files. The project's data clerks work closely with the HMIS clerks to ensure the necessary information is collected for both routine reporting in the HMIS registers and database entry. The 'champion' CO is available for assistance with interpreting the clinical file.

The admitted patients are then followed throughout their hospital stay. The study data clerks move throughout the paediatric inpatient wards to collect follow-up and outcome data and to identify patients who may have been admitted without passing through U5. They record the dates that radiology investigations, labs and specialist 
Table 2 Variables being collected in the paediatric acute care database (as of January 2020). This list of variables includes what was suggested in the questionnaire answers and verbal feedback provided by stakeholders.

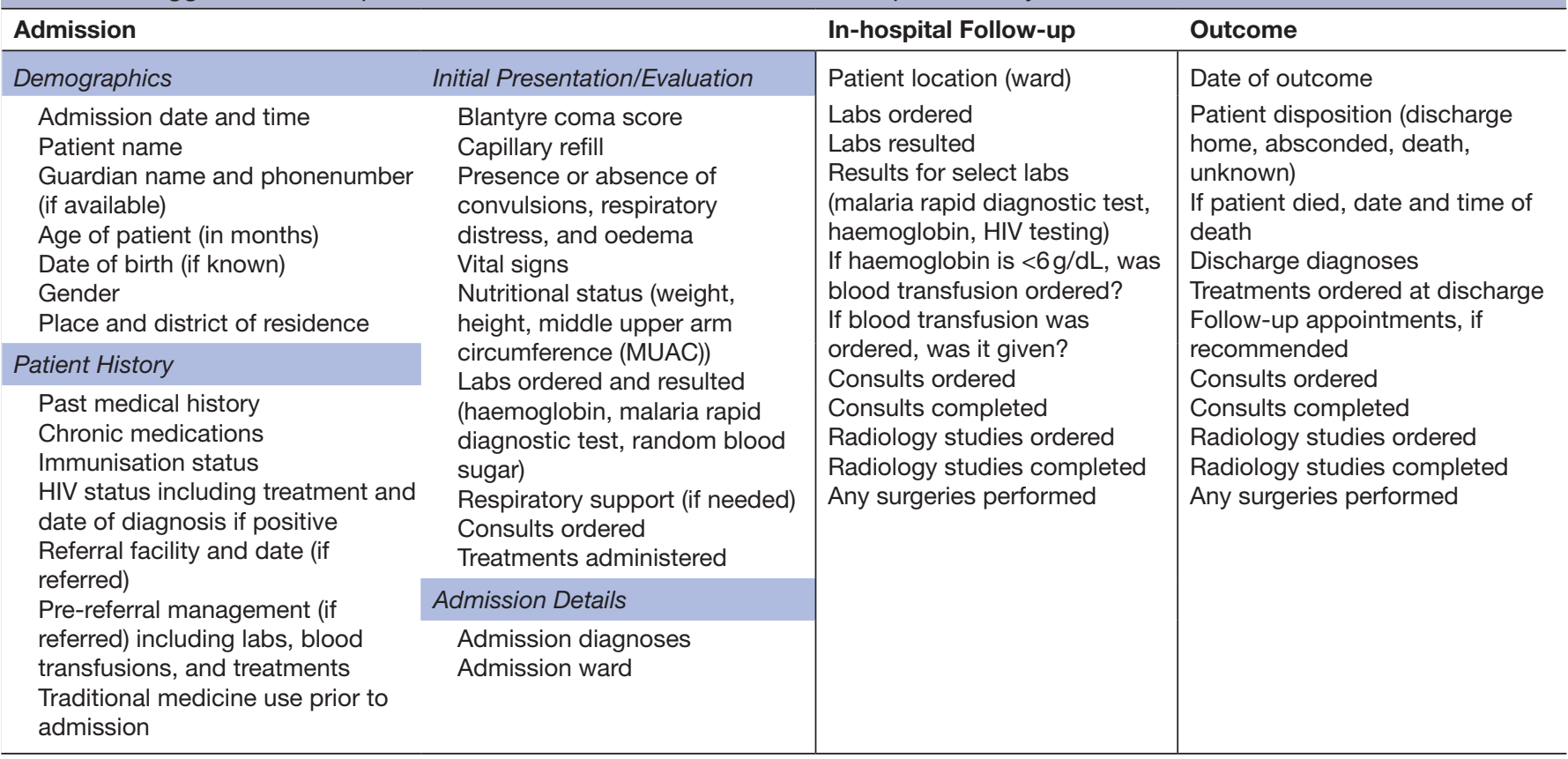

consults are ordered and resulted through review of the clinical files and discussions with patient guardians. They document patient disposition and discharge diagnoses through review of clinical charts and register books and attendance at the departmental handover each morning. Most data are entered directly into the database records on the tablets, although paper versions of the forms remain available in case of technical difficulties.

\section{Data quality and access}

A project manager supervises the data clerks, provides administrative support and audits $10 \%$ of all the discharges each month, comparing the data entered in REDCap with what is documented in the clinical files. The clinical champion also audits all patient deaths. Feedback regarding data entry errors, most commonly small typographical errors, is provided to each data clerk, and they make corrections accordingly in REDCap.

The database is readily available in deidentified form to the KCH Paediatrics Department leadership and any interested clinical providers or staff. Reports are generated and disseminated to the department monthly, and the data are presented at the paediatric handover meeting every 2 months. Data are also accessible by US-based investigators from the PACHIMAKE institutions.

\section{Current use}

The data obtained have provided baseline information for several ongoing QI and hypothesis-driven projects. For instance, it was noted that approximately 15\%-20\% of patients were not tested for HIV despite the presence of a specific team whose charge is to test all paediatric inpatients. This led to a root cause analysis and implementation of improved communication between the HIV testing team and database data clerks to identify untested children and consistently document results in the same place in the patient files. Additionally, investigators have sought to understand the epidemiology of severe anaemia and the effect of blood transfusion on patient outcomes. This work has led to Geographic Information System mapping of the health facilities from which patients with severe anaemia were referred to identify those that have higher rates of severe anaemia and mortality following transfer to $\mathrm{KCH}$. Finally, data regarding severe acute malnutrition (SAM) have shown that, despite the documentation of anthropometric measurements consistent with SAM, the diagnosis of SAM itself is not documented (and presumably not recognised) $60 \%$ of the time. ${ }^{46}$ This lack of recognition likely leads to inappropriate management and adverse events in a cohort already at increased risk of poor patient outcomes; our data support that overall adherence to the WHO's 10 steps for management of SAM is low. Current interventions targeting improved recognition and management of SAM are underway, and their impact will be assessed using the database.

\section{Challenges and limitations}

Throughout the development, implementation and maintenance of this database, we faced obstacles (table 3). Obtaining funding to augment an existing system with the goal of improving data quality, but without a primary research focus, was difficult. This challenge limited the patient population initially included in the database. There was an initial misconception among those involved in the HMIS system that the database was being designed to replace, as opposed to augment and collaborate with, their existing data collection process. This was 
Table 3 Challenges and strategies developed in response during the process of developing and implementing the $\mathrm{KCH}$ Paediatric Emergency and Acute Care Registry

\begin{tabular}{|c|c|}
\hline Challenge & Strategies/Lessons Learnt \\
\hline Need for integration into existing HMIS system & $\begin{array}{l}\text { Multiple meetings with HMIS leadership were key to designing } \\
\text { an integrated and complementary process } \\
\text { Inclusion of HMIS data clerks into PACHIMAKE data clerk } \\
\text { trainings } \\
\text { Physical placement of PACHIMAKE data clerks next to the } \\
\text { HMIS data clerks to encourage collaboration and teamwork } \\
\text { Frequent bidirectional communication with the HMIS staff }\end{array}$ \\
\hline Importance of local ownership of the project & $\begin{array}{l}\text { Project designed to fulfil need identified by KCH Paediatric } \\
\text { Department administration } \\
\text { Appointment of a clinician champion } \\
\text { Local project manager to supervise data clerks and } \\
\text { troubleshoot day-to-day challenges }\end{array}$ \\
\hline Multiple patient entry and exit points/paths & $\begin{array}{l}\text { Data clerks perform 'liwamba' (Chichewa for a 'hunt') twice per } \\
\text { shift to locate and follow admitted patients } \\
\text { - Re-education of staff to direct patients to U5 } \\
\text { - Placement of data clerks at most common entry point (U5) }\end{array}$ \\
\hline Ensuring data quality & $\begin{array}{l}\text { Targeted trainings for data clerks } \\
\text { Periodic reassessment of vital sign and anthropometric } \\
\text { measurement skills } \\
\text { Monthly audits of deaths and } 10 \% \text { of discharges with feedback } \\
\text { to the clerks } \\
\text { Cross-checking of ward and database registers of discharged } \\
\text { and deceased patients }\end{array}$ \\
\hline
\end{tabular}

HMIS, Health Management Information System; KCH, Kamuzu Central Hospital; PACHIMAKE, Paediatric Alliance for Child Health Improvement in Malawi at $\mathrm{KCH}$ and Environs; U5, Under 5.

unexpected and unintended and led us to more thoroughly and frequently engage with the HMIS leadership in our planning process. Additionally, we have sought to consider the HMIS and PACHIMAKE data clerks as one group, encouraging all members to participate in trainings related to the database. Occasionally, technical issues arose with REDCap, and we have frequently engaged the support of the local and remote information technology staff. We are still working on the most productive and efficient way to encourage and facilitate the use of the data to inform local care algorithms or policies by Malawian clinicians and administrators. Time constraints and the burdens of daily clinical care likely limit this engagement. Finally, due to financial and logistical limitations, the database was not designed to be an electronic medical record that would allow for real-time visibility and accessibility of clinical data by clinicians; they still rely on the paper forms for day-to-day care. It also does not yet interface with national-level health information systems, which has been identified by the $\mathrm{MOH}$ as a key aspect of reporting systems. ${ }^{33}$

\section{Future directions}

Our goal is to engage more Malawian clinicians and investigators to use the database to answer questions pertinent to their clinical practice and guide further QI initiatives. This engagement will, in part, occur through a workshop on manuscript development and research skills in spring 2020. Potential areas of focus include mapping of referring facilities to identify those that are associated with high risk of mortality following transfer to $\mathrm{KCH}$, assessment of pneumonia management as compared with WHO standards of care, and rates of readmission by discharge diagnosis. In addition, we would like to link our database to the DHIS2 system as it is expanded to tertiary hospitals, an endeavour that is currently in the initial planning phase. We are currently working to train the HMIS clerks on the use of the tablets and the database to build their capacity.

\section{CONCLUSIONS}

Here, we report the development and implementation of an electronic database of paediatric emergency and acute care in Malawi. We demonstrate that creating and implementing a clinical database in a busy paediatric inpatient ward is feasible. Keys to its success include engagement of a broad range of stakeholders early in the planning process and a thorough evaluation of current health information systems at the hospital level to ensure the 
planned activities enhance and do not impede existing processes. In addition, the intentional development of a robust data collection system that covers an entire ward, rather than focusing on a specific disease process, supports both quality efforts and hypothesis-driven research. Our database is providing valuable information regarding paediatric patients at $\mathrm{KCH}$ and baseline data for assessment of QI initiatives' impact. We believe that others who seek to improve the quality of data at LMIC may face similar challenges and offer our experience as one approach to the problem. In the future, it will be important that our database efficiently interface with DHIS2 to ensure its maximum utility and sustainability.

\section{Author affiliations}

${ }^{1}$ Division of Infectious Diseases, Department of Medicine, University of North Carolina School of Medicine, Chapel Hill, North Carolina, USA

${ }^{2}$ Departments of Medicine and Pediatrics, University of North Carolina School of Medicine, Chapel Hill, North Carolina, USA

${ }^{3}$ Department of Paediatrics, Kamuzu Central Hospital, Lilongwe, Malawi

${ }^{4}$ Department of Pediatrics, University of Cincinnati College of Medicine, Cincinnati, Ohio, USA

${ }^{5}$ Department of Information Communication Technology, Kamuzu Central Hospital, Lilongwe, Malawi

${ }^{6}$ Department of Pediatrics, Baylor College of Medicine, Houston, Texas, USA

${ }^{7}$ Division of Pediatric Emergency Medicine, University of Utah Health, Salt Lake City, Utah, USA

${ }^{8}$ Departments of Pediatrics and Family/Community Medicine, University of Cincinnati College of Medicine, Cincinnati, Ohio, USA

${ }^{9}$ UNC Project-Malawi, Lilongwe, Malawi

${ }^{10}$ Department of Pediatrics, University of North Carolina School of Medicine, Chapel Hill, North Carolina, USA

${ }^{11}$ Division of Emergency Medicine, Department of Pediatrics, University of North Carolina School of Medicine, Chapel Hill, North Carolina, USA

Acknowledgements This project would not have been possible without the PACHIMAKE database team of clerks, clinicians and managers. We would also like to thank UNC Project-Malawi for their administrative support, the KCH HMIS team, and the clinical staff and patients on the paediatric wards at $\mathrm{KCH}$.

Collaborators This work was done on behalf of the PACHIMAKE consortium.

Contributors EJC and AET planned and conducted the work described and drafted, revised and finalised the manuscript. MCK, YM, HN and TM planned the project, assisted with conducting the work described and revised the manuscript. ME, HLC, JAR and CJS planned the project and contributed to and revised the manuscript. TBM assisted with conducting the work described and revised the manuscript. EF supervised the project, contributed to the planning and implementation of the work described as well as the drafting and revising of the manuscript.

Funding The majority of the funding for this work came from donations to UNC Children's Initiative of UNC Health Foundation, the organisation that receives philanthropic gifts to the UNC School of Medicine. This project was also in part supported by scholarships (EJC and AET) and the Global Health Scholars Program (EJC) from the UNC Office of Global Health Education. Finally, through use of REDCap, this work was supported by the National Center for Advancing Translational Sciences (NCATS), National Institutes of Health (NIH), through Grant Award Number UL1TR001111. The content is solely the responsibility of the authors and does not necessarily represent the official views of the NIH.

Competing interests None declared.

Patient consent for publication Not required.

Provenance and peer review Not commissioned; externally peer reviewed.

Data availability statement The survey data from the stakeholder assessments, as well as paper and/or electronic versions of the paediatric database data collection forms, are available from the corresponding author upon reasonable request.
Open access This is an open access article distributed in accordance with the Creative Commons Attribution Non Commercial (CC BY-NC 4.0) license, which permits others to distribute, remix, adapt, build upon this work non-commercially, and license their derivative works on different terms, provided the original work is properly cited, appropriate credit is given, any changes made indicated, and the use is non-commercial. See: http://creativecommons.org/licenses/by-nc/4.0/.

\section{ORCID iDs}

Emily J Ciccone http://orcid.org/0000-0003-2445-8473

Elizabeth Fitzgerald http://orcid.org/0000-0001-7002-4700

\section{REFERENCES}

1 Liu L, Oza S, Hogan D, et al. Global, regional, and national causes of under-5 mortality in 2000-15: an updated systematic analysis with implications for the sustainable development goals. The Lancet 2016;388:3027-35.

2 Hsia R, Razzak J, Tsai AC, et al. Placing emergency care on the global agenda. Ann Emerg Med 2010;56:142-9.

3 Molyneux E. Emergency care for children in resource-constrained countries. Trans R Soc Trop Med Hyg 2009;103:11-15.

4 Hategeka C, Shoveller J, Tuyisenge L, et al. Assessing process of paediatric care in a resource-limited setting: a cross-sectional audit of district hospitals in Rwanda. Paediatr Int Child Health 2018;38:137-45.

5 Nolan T, Angos P, Cunha AJ, et al. Quality of hospital care for seriously ill children in less-developed countries. Lancet 2001;357:106-10.

6 Molyneux EM. Paediatric emergency care in resource-constrained health services is usually neglected: time for change. Ann Trop Paediatr 2010;30:165-76.

7 Duke T, Cheema B. Paediatric emergency and acute care in resource poor settings: paediatric acute care in developing countries. $J$ Paediatr Child Health 2016;52:221-6.

8 Kruk ME, Gage AD, Arsenault C, et al. High-Quality health systems in the sustainable development goals era: time for a revolution. Lancet Glob Health 2018;6:e1196-252.

9 Anderson PD, Suter RE, Mulligan T, et al. World health assembly resolution 60.22 and its importance as a health care policy tool for improving emergency care access and availability globally. Ann Emerg Med 2012;60:35-44.

10 Razzak J, Beecroft B, Brown J, et al. Emergency care research as a global health priority: key scientific opportunities and challenges. BMJ Glob Health 2019;4:e001486.

11 Campbell H, Duke T, Weber M, et al. Global initiatives for improving hospital care for children: state of the art and future prospects. Pediatrics 2008;121:e984-92.

12 English M, Esamai F, Wasunna A, et al. Assessment of inpatient paediatric care in first referral level hospitals in 13 districts in Kenya. Lancet 2004;363:1948-53.

13 Chan M, Kazatchkine M, Lob-Levyt J, et al. Meeting the demand for results and accountability: a call for action on health data from eight global health agencies. PLoS Med 2010;7:e1000223.

14 Evaluation M. Routine health information systems: a curriculum on basic concepts and practice. Chapel Hill, NC: University of North Carolina, 2017. https://www.measureevaluation.org/our-work/ routine-health-information-systems/rhis-curriculum

15 Mbondji PE, Kebede D, Soumbey-Alley EW, et al. Health information systems in Africa: descriptive analysis of data sources, information products and health statistics. J R Soc Med 2014;107:34-45.

16 Health Data Collaborative. Progress report 2016-2017: highlights, lessons learned, future perspectives, 2017. Available: https://www. healthdatacollaborative.org/fileadmin/uploads/hdc/Documents/Heal thDataCollaborative Progress Report_2016-2017.pdf [Accessed 12 Apr 2020].

17 Akanbi MO, Ocheke AN, Agaba PA, et al. Use of electronic health records in sub-Saharan Africa: progress and challenges. J Med Trop 2012;14:1-6.

18 Mbondji PE, Kebede D, Soumbey-Alley EW, et al. Resources, indicators, data management, dissemination and use in health information systems in sub-Saharan Africa: results of a questionnaire-based survey. J R Soc Med 2014;107:28-33.

19 Brault MA, Mwinga K, Kipp AM, et al. Measuring child survival for the millennium development goals in Africa: what have we learned and what more is needed to evaluate the sustainable development goals? Glob Health Action 2020;13:1732668.

20 Eckerle M, Crouse HL, Chiume M, et al. Building sustainable partnerships to strengthen pediatric capacity at a government hospital in Malawi. Front Public Health 2017;5:183.. 
21 Petroze RT, Byiringiro JC, Kyamanywa P, et al. Infectious outcomes assessment for health system strengthening in low-resource settings: the novel use of a trauma registry in Rwanda. Surg Infect 2014:15:382-6.

22 Chichom-Mefire A, Nwanna-Nzewunwa OC, Siysi V, et al. Key findings from a prospective trauma registry at a regional hospital in Southwest Cameroon. PLoS One 2017;12:e0180784.

23 O'Hagan R, Marx MA, Finnegan KE, et al. National assessment of data quality and associated Systems-Level factors in Malawi. Glob Health Sci Pract 2017;5:367-81.

24 SanJoaquin MA, Allain TJ, Molyneux ME, et al. Surveillance programme of in-patients and epidemiology (spine): implementation of an electronic data collection tool within a large hospital in Malawi. PLoS Med 2013;10:e1001400.

25 Fraser $\mathrm{H}$, Biondich $\mathrm{P}$, Moodley $\mathrm{D}$, et al. Implementing electronic medical record systems in developing countries. Jhi 2005;13:83-95.

26 Kavuma M. The usability of electronic medical record systems implemented in sub-Saharan Africa: a literature review of the evidence. JMIR Hum Factors 2019;6:e9317.

27 Day LT, Ruysen H, Gordeev VS, et al. "Every Newborn-BIRTH" protocol: observational study validating indicators for coverage and quality of maternal and newborn health care in Bangladesh, Nepal and Tanzania. J Glob Health 2019;9:010902.

28 Little P, Stuart B, Francis N, et al. Effects of Internet-based training on antibiotic prescribing rates for acute respiratory-tract infections: a multinational, cluster, randomised, factorial, controlled trial. The Lancet 2013;382:1175-82.

29 Kuo BJ, Vaca SD, Vissoci JRN, et al. A prospective neurosurgical registry evaluating the clinical care of traumatic brain injury patients presenting to Mulago national referral hospital in Uganda. PLoS One 2017; 12:e0182285.

30 Hazel E, Wilson E, Anifalaje A, et al. Building integrated data systems for health and nutrition program evaluations: lessons learned from a multi-country implementation of a DHIS 2-based system. J Glob Health 2018;8:020307.

31 Tuti T, Bitok M, Paton C, et al. Innovating to enhance clinical data management using non-commercial and open source solutions across a multi-center network supporting inpatient pediatric care and research in Kenya. J Am Med Inform Assoc 2016;23:184-92

32 Government of Malawi National Statistical Office. Population and housing census: preliminary report, 2018. Available: https://malawi. unfpa.org/sites/default/files/resource-pdf/2018 Census Preliminary Report.pdf[Accessed 7 Nov 2019].

33 Government of the Republic of Malawi. Health sector strategic plan II 2017-2022: towards universal health coverage., 2017. Available: https://www.health.gov.mw/index.php/policies-strategies? download=47:malawi-health-sector-strategic-plan-ii-2017-2022 [Accessed 12 Apr 2020].

34 Hamer J. The right choices: achieving universal health coverage in Malawi. Oxfam GB for Oxfam international, 2016. Available: https:// oxfamilibrary.openrepository.com/bitstream/handle/10546/611820/ bn-right-choices-universal-health-coverage-malawi-070616-en.pdf [Accessed 12 Apr 2020].

35 Robison J, Ahmed Z, Durand C, et al. Implementation of ETAT (emergency triage assessment and treatment) in a central hospital in Malawi. Arch Dis Child 2011;96:A74-5.

36 Robison JA, Ahmad ZP, Nosek CA, et al. Decreased pediatric hospital mortality after an intervention to improve emergency care in Lilongwe, Malawi. Pediatrics 2012;130:e676-82.

37 Dehnavieh R, Haghdoost A, Khosravi A, et al. The district health information system (DHIS2): a literature review and meta-synthesis of its strengths and operational challenges based on the experiences of 11 countries. Him J 2019;48:62-75.

38 Government of Malawi Ministry of Health. Malawi National health information system policy. Lilongwe, Malawi, 2015. https://www.heal thdatacollaborative.org/fileadmin/uploads/hdc/Documents/Country documents/September_2015_Malawi_National_Health_Information_ System_Policy.pdf

39 Chikumba PA. Management of health information in Malawi: role of technology. Adv. sci. technol. eng. syst. j. 2017;2:157-66.

40 Amouzou A, Kachaka W, Banda B, et al. Monitoring child survival in 'real time' using routine health facility records: results from Malawi. Trop Med Int Health 2013;18:1231-9.

41 Fitzgerald E, Mlotha-Mitole R, Ciccone EJ, et al. A pediatric death audit in a large referral hospital in Malawi. BMC Pediatr 2018;18.

42 Kendig CE, Samuel JC, Varela C, et al. Pediatric surgical care in Lilongwe, Malawi: outcomes and opportunities for improvement. $J$ Trop Pediatr 2014;60:352-7.

43 Matoga MM, Rosenberg NE, Stanley CC, et al. Inpatient mortality rates during an era of increased access to HIV testing and art: a prospective observational study in Lilongwe, Malawi. PLoS One 2018;13:e0191944.

44 Chawla KS, Rosenberg NE, Stanley C, et al. Hiv and early Hospital readmission: evaluation of a tertiary medical facility in Lilongwe, Malawi. BMC Health Serv Res 2018;18:225.

45 Harris PA, Taylor R, Thielke R, et al. Research electronic data capture (REDCap)-A metadata-driven methodology and workflow process for providing translational research informatics support. J Biomed Inform 2009;42:377-81.

46 Vonasek BJ, Chiume M, Crouse HL, et al. Risk factors for mortality and management of children with complicated severe acute malnutrition at a tertiary referral hospital in Malawi. Paediatr Int Child Health 2020;17:1-10. 